\title{
Connected Enterprise Meets Connected Customer - A Design Approach
}

\author{
Marcus Fischer \\ University of Würzburg \\ marcus.fischer@uni- \\ wuerzburg.de
}

Axel Winkelmann

University of Würzburg

axel.winkelmann@uni-

wuerzburg.de

\author{
Florian Imgrund \\ University of Würzburg \\ florian.imgrund@,uni- \\ wuerzburg.de
}

\author{
Gregor Friedrich-Baasner \\ University of Würzburg \\ gregor.friedrich-baasner@uni- \\ wuerzburg.de
}

\author{
Christian Janiesch \\ University of Würzburg \\ christian.janiesch@uni- \\ wuerzburg.de
}

\begin{abstract}
In an increasingly digitized environment, enterprises face new challenges. Enabled by ubiquitous Internet accessibility, people, places, and products have become more interconnected and are gradually merging into the Internet of Everything. Simultaneously, a new generation of connected customers is emerging that is establishing new requirements for the capabilities of enterprises to communicate, interact, and respond to unforeseen events. As customer satisfaction is the central source of future competitiveness, companies must initiate a transformation towards a connected enterprise. By analyzing the characteristics of the connected customer, this paper presents guidelines for enterprises to address customer needs adequately and manage their operations in the Internet of Everything. Building upon established enterprise architecture frameworks, we apply a Design Science Research procedure to derive four practical recommendations. Thus, enterprises must manage their business processes holistically, implement information systems and standards for data exchange, provide mechanisms for real-time business intelligence, and determine their optimal degree of connectivity.
\end{abstract}

\section{Introduction}

Low prices, high-quality products, and innovative marketing activities were among the key drivers for the competitiveness of enterprises in an analogous economic environment. However, as technology has advanced significantly in recent years, organizations face unknown challenges when interacting with increasingly connected customers (CC), which changes the product lifecycle twofold. First, purchasing decisions are influenced by an unlimited amount of available information that redefines the traditional customer journey. Second, customers demand more sophisticated products and services that address their individual needs throughout the entire product lifecycle. To provide satisfactory product experiences, enterprises rely on the effective management of customer-oriented aftersales activities, while the process of simply selling a product has become less important. Consequently, former key drivers of business success become fundamental requirements. To address corresponding challenges, enterprises must adapt, reorganize, and improve their business operations continuously and integrate new technologies into their current organizational structure. Enabled by ubiquitous Internet accessibility, all areas of our daily life are increasingly digitized and supported by corresponding products and services [10]. Further facilitated by emerging technologies, such as social networks, micro blogging services, and meta-search engines, the Internet, which was traditionally used as a one-way source for users to collect relevant information, has become a bidirectional communication platform that enables customers to interact with each other and their environment [33]. The share of Internet compatible products is rapidly growing and, thus, collecting, storing, and analyzing enormous amounts of data on customer behavior has become more feasible [24]. Furthermore, customers can share and distribute experiences among each other immediately. Consequently, product characteristics that were usually uncovered during the phase of product usage, are available through reviews, ratings, and customer experiences that are distributed over various communication channels today [39].

As customers require more service-centricity, stand-alone products are replaced by hybrid productservice-combinations [29]. Thus, product benefits are not based exclusively on product design and functionality, but rather are influenced extensively by 
the availability and quality of complementary services. Consequently, potential benefits of product usage are relocated to subsequent phases of the traditional product lifecycle. Digitization further increases the pressure on an enterprise's underlying business model, strategy, and key activities for value creation. Numerous industries, such as the IT and telecommunication industry, have already undergone a fundamental transformation process in recent years [13]. While mobiles phones were traditionally only used as communication devices, they combine functionalities of personal computers as well as complementary services for a wide range of user purposes today. Consequently, key drivers of customer satisfaction have gradually shifted from efficiently manufacturing, distributing, and selling products, to providing an intuitive usability, an open software development environment, and the utilization of network effects [34].

As satisfying customers becomes a highly complex task, enterprises are facing unknown challenges. However, in a digitized environment, in which customers are interconnected and share views, opinions, and experiences, customer satisfaction is likely to become the central source of competitiveness. While this especially applies to industries with substitutable products and a competitive market structure, the underlying transformation process tends to eventually alter all types of markets and industries. To address these challenges, the present paper aims to provide enterprises with a blueprint for an enterprise architecture that facilitates customer satisfaction within this complex environment. We summarize our research question as follows:

"How can we adapt enterprise architectures to address the requirements of connected customers in a digitized business environment?"

To answer this research question, we follow a Design Science Research (DSR) procedure to develop our contribution [7]. As our research progressed, we iteratively performed the configuration of our artifact. It has explanatory power as well as provides design practice theory for the design and improvement of approaches that aim to improve business operations when interacting with the CC.

The paper is organized as follows: Section 2 briefly describes the applied research methodology. In Section 3, we introduce current enterprise architectures and derive a set of necessary reference layers and corresponding artifacts. Section 4 describes how customers connect with their environment and presents a collection of influence factors that are crucial for addressing the needs of the CC. Subsequently, we analyze the interactions between customers and enterprises in a digital environment in Section 5. In Section 6, we further provide methods, tools, and technologies to implement the predefined layers and artifacts. Ultimately, Section 7 concludes this research with a summary of findings, limitations, and future research potentials.

\section{Research method}

To answer our research question, we used a DSR procedure, which typically comprises six iterative steps, including problem identification, the definition of objectives, design and development, demonstration, evaluation, and communication [42].

We aim to address the problem of aligning predominant organizational structures to the changing demands of the CC. Thus, we seek to define a set of practical guidelines for enterprises and transform these procedures into an integrated concept by drawing upon existing enterprise architectures. During the design and development phase, we investigate real-world data to identify and structure emerging customer needs in the era of digitization. We further adapt the concept of service blueprinting to conceptualize interactions between customers and enterprises and reduce the manifold requirements to a set of four practical recommendations. To ensure their applicability and interoperability, we then transform these guidelines into an integrated enterprise architecture by providing suitable artifacts for each architectural layer. Finally, we evaluate our findings with domain experts that analyze our design recommendations towards their practical applicability and suitability to address the requirements of the $\mathrm{CC}$.

\section{Enterprise architectures}

Enterprise Architectures (EA) generally define the fundamental organization of an enterprise and its way of interacting with partners, suppliers, and customers [53]. EA bridge an enterprise's technological and organizational dimensions and facilitate the attainment of an integrated view of its informational resources $[38,55]$. Based on the mutual alignment of strategic goals, performance measures, and information system usage, EA constitute an adequate starting point for the effective management of business operations $[12,46]$.

While EA describe an enterprise's as-is or to-be structure, corresponding EA frameworks (EAF) provide meta-models for their construction, methods for their design and refinement, and ontologies, as well as reference models that can serve as an integrative blueprint [47]. In a changing business environment, 
EAF can provide a framework to adapt current organizational structures.

Numerous EAF that have been developed in recent years share similar goals, artifacts, and layers [48]. However, many frameworks are designed for specific stakeholders. [56] initially introduced an EAF to provide a logical construct to organize an enterprise's resources. Following the principles of traditional architectures, the Zachman Framework provides a common vocabulary and six perspectives to describe complex enterprise systems. Based on the dimensions "Planner," "Owner," "Designer," "Builder," "Subcontractor," and "User," the framework addresses the scope and business model of an enterprise and its technological infrastructure [48]. It further provides layer-specific artifacts as detailed representations of each perspective and aims to implement a functioning system for its users. However, the Zachman Framework does not provide guidance on sequences, processes, or its implementation, and specifies no explicit rules for its compliance.

To address informational needs of international military operations, the Department of Defense Architecture Framework (DoDAF) provides operational, system-related, and technical guidelines [47]. While the operational view specifies interdependencies of real-world objects, the systemrelated view defines information systems and corresponding interfaces for information exchange [2]. The framework further refines its architectural components within the technical dimension. Finally, the system view serves as an integrative layer by providing a terminological dictionary as well as supplementary information [48].

To assist governmental institutions in developing complex information systems, the Federal Enterprise Architecture Framework (FEAF) defines rules that specify the development, maintenance, and implementation of integrated architectures. Thus, the FEAF fosters an efficient organization of information, while enabling it to be shared within the Federal Government. Based on these structured guidelines, necessary architectural components are developed individually, representing its own enterprise within the federal organization. FEAF further provides flexibility, as it offers methods, instruments, and tools for each federal agency. Accordingly, the Treasury Enterprise Architecture Framework (TEAF) aims to analyze interdependencies and information flows in the organizational structure of the Department of Treasury to manage its IT resources effectively. Thus, it determines common requirements across different treasury offices to enable information sharing and the integration of data and administrative processes.
Ultimately, the Open Group Architectural Framework (TOGAF) provides an approach for designing, planning, implementing, and governing an enterprise architecture [15]. It is organized along an enterprise's business model, applications, data, and technologies, and builds upon modularization, standardization, and proven technologies and products [47]. First, the business architecture defines an enterprise's strategy, governance, organization, and key processes. Second, the data architecture describes structural characteristics of logical and physical data assets and establishes data management methods. Third, the application layer serves as a blueprint for the deployment of individual systems and defines interfaces for information exchange. Finally, the technical architecture comprises an enterprise's hardware, software, and network infrastructure. It is considered as a refinement of the DoDAF, and introduces the Architectural Development Method as a key element to define recommendations for architecture development, without explicitly providing definite design principles.

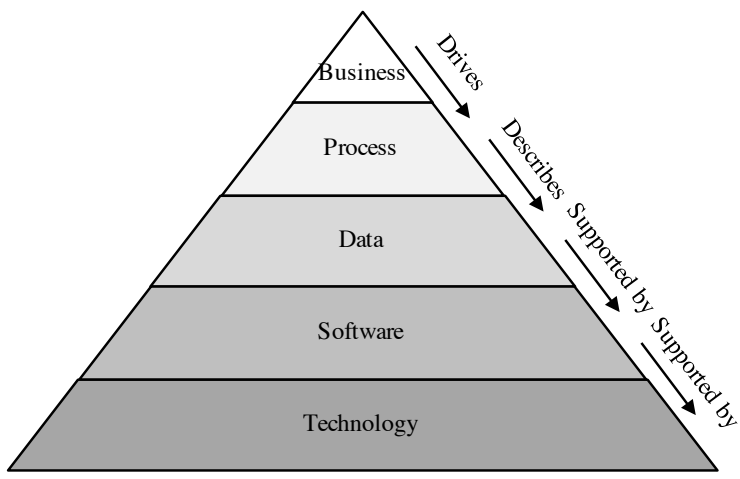

Figure 1. Components of EAF [53]

Although we identified several EAF within the literature, no common understanding of an architecture's layers and artifacts exist [53]. As we aim to provide generalizable implications on how to address customer requirements in a digitized environment, we follow [53], who define EA as multilevel systems and provide reference structures and artifacts for each layer. As illustrated in Figure 1, EAF typically comprise the five components of business, process, data, software, and technology. First, the business architecture describes an enterprise's organization from a strategical perspective [53]. Thus, it specifies the process of value creation, customer relationship management, targeted market segments, offered services, and organizational goals. As it determines the scope of business activities, it defines the requirements for the subsequent design and implementation of information systems. Second, the 
process architecture summarizes relevant preliminaries for service development, service creation, and service distribution, aiming to improve the effectivity and efficiency of business operations [53]. Consequently, enterprises must establish an adequate documentation of their organizational structure, for example, by developing semi-formal representations of business processes, business units, and responsibilities. Third, the integration of data and processes is specified in the integration architecture [53]. Thus, enterprises must examine their services, application clusters, integration systems, and data flows. Designing the integration architecture, they aim to improve cost efficiency, for example, by reducing system interfaces to achieve more data and process integration, and to increase the speed of inter-organizational and intra-organizational procedures [53]. Fourth, the software architecture comprises software artifacts that support enterprises in addressing organizational needs and in providing an appropriate quality of business operations. Ultimately, the technological architecture summarizes the general IT infrastructure of an enterprise and provides necessary hardware for computation tasks and communication purposes. While the identified architectures provide a blueprint for an enterprise's structure, they do not specify the technologies necessary to address the changing requirements of a company's business environment. Due to their focus on internal operations, they further provide only limited guidance for emerging phenomena, including the $\mathrm{CC}$, an increasing integration across supply chain participants, and the availability of ubiquitous communication channels. Thus, we aim to extend the provided design principles of established EA through a set of facilitating technologies that improve organizational responsiveness and support companies in addressing the previously introduced challenges.

\section{Requirements of the connected customer}

Driven by a ubiquitous Internet accessibility and the ongoing advancements in information technology, the physical and virtual world are gradually merging into the integrated Internet of Everything (IoE) [50].

First, the Internet of People (IoP) summarizes the computerization of social interactions, based on the increasing distribution and usage of communication technologies, such as social networks or instant messaging [36]. Thus, people can share opinions, experiences, and knowledge centrally and in real time. By revealing traditionally hidden customer preferences by collecting, storing, and analyzing personal data, enterprises can capture benefits by aligning their operations, products, and services to customer needs [1]. However, as social networks are characterized by a rapid diffusion of information, significant risks can result from the distribution of negative customer experiences [3]. To address these challenges and to avoid a sustainable loss of reputation, enterprises must achieve an organization-wide integration of data and business processes [32]. Thus, they must implement technologies and mechanisms that facilitate their responsiveness to negative events and developments [6]. Furthermore, holistic strategies to reduce and/or avoid mistakes during the value creation process are necessary.

Second, the Internet of Locations (IoL) describes the computerization of places, enabled by locationbased services (LBS) [37]. Although the Internet originally resulted in globalization and anonymization, LBS offer the opportunity to address customer needs locally based on geospatial customer data [44]. By analyzing spatial patterns, enterprises can acquire an in-depth understanding of customer behavior tied to a specific location. However, most LBS are characterized by their customer-sided initiation. Thus, their use is frequently limited to static information queries, for example, by using search engines to find local offerings. By contrast, proactive LBS automatically push location-based content, while accounting for user-specific preferences derived from the simultaneous analysis of multiple information sources. However, as offering proactive LBS is a complex endeavor, enterprises face new challenges regarding their information system architecture. From a technical perspective, LBS require an integration of mobile devices, data networks, service providers, and users [4]. Simultaneously, enterprises must collect, store, structure, prioritize, and analyze data from multiple sources in real time, which can exceed current capabilities of data processing systems.

Eventually, the Internet of Things (IoT) describes connected objects that can collect and exchange data through integrated electronics, software, sensors, effectors, and network activity [21]. Based on the IoT, new opportunities emerge to integrate the physical world into cyber-physical systems more directly and to accomplish improvements in efficiency, accuracy, and economic benefits, while reducing the necessity for human interventions [43, 49]. However, as customer requirements become more service-centered, traditional product features become less important [54]. Today, product success relies heavily on the availability of complementary software applications, software usability, and the utilization of network effects. Additionally, enterprise activities, such as manufacturing and logistics, are increasingly computerized and data-driven [22, 35]. As competition increases, enterprises must focus on their core activities and traditionally linear value chains are being 
replaced by value networks. Thus, enterprises must reengineer their business operations, establish new organizational competencies, and integrate data and processes throughout the entire supply chain.

As the IoE integrates people, products, and enterprises, customer characteristics change due to their participation in a digitized environment. Frequently referred to as digital natives, the socialization process of modern-day customers is significantly influenced by the availability and usage of personal computers, email, the Internet, mobile devices, and instant messaging [41]. Consequently, the ubiquitous accessibility of digital applications, tools, and devices, results in changing behavioral patterns and increased capabilities to process information from multiple sources. As influence factors, such as data privacy and security, become less relevant, customers demand products and services to offer more benefits in the dimensions of efficiency and effectivity. While all requirements significantly influence customer satisfaction, distinct interdependencies can result in conflicts between different dimensions. Especially when interacting with the $\mathrm{CC}$, enterprises must continuously evaluate changing customer preferences and adjust their product-service-combinations accordingly. The present paper summarizes these changing customer characteristics by specifying the CC, whose needs are summarized in Table 1.

Table 1. Characteristics of the CC [45]

\begin{tabular}{|l|l|}
\hline Characteristic & Description \\
\hline Position & $\begin{array}{l}\text { Reveals location-based data if valuable } \\
\text { services are offered in return. }\end{array}$ \\
\hline Information search & $\begin{array}{l}\text { Expects integrated information during } \\
\text { the entire purchasing process. }\end{array}$ \\
\hline Relationships & $\begin{array}{l}\text { Establishes close relationships with } \\
\text { enterprises within similar views. }\end{array}$ \\
\hline Communication & $\begin{array}{l}\text { Takes responsibility for other } \\
\text { customers by sharing experiences. }\end{array}$ \\
\hline Personalization & $\begin{array}{l}\text { Prefers individualized products and } \\
\text { services. }\end{array}$ \\
\hline Thoughts & $\begin{array}{l}\text { Requires clear privacy rules and strict } \\
\text { compliance. }\end{array}$ \\
\hline Participation & $\begin{array}{l}\text { Seeks to participate in designing and } \\
\text { developing new products and services. }\end{array}$ \\
\hline Integration & $\begin{array}{l}\text { Uses experiences of other customers to } \\
\text { enrich purchasing decisions. }\end{array}$ \\
\hline
\end{tabular}

As customer satisfaction is likely to become the most important source of competitiveness, enterprises must initiate a transformation towards a connected enterprise. Subsequently, we introduce four guidelines that aim to provide guidance in designing and implementing an adequate enterprise architecture:
1. Implement a decentralized process management initiative

2. Minimize coordination and communication costs

3. Analyze business operations in real time

4. Determine the optimal degree of connectivity

We derived these guidelines by following an inductive reasoning approach. First, we analyzed multiple practical studies to identify current challenges of enterprises that result from digitization. We focused on small and medium-sized enterprises, as they typically have not finished their digital transformation yet. Second, we analyzed empirical studies on the characteristics and requirements of digital natives and other emerging customer segments, linked them to the predefined challenges, and determined the EAF components they affect. Ultimately, we aimed to define guidelines that simultaneously address all EAF components, challenges, and requirements and prioritized them due to their benefits, feasibility, and complexity during implementation.

\section{Customer-Enterprise interactions}

Instead of assigning specific departments to provide analogous customers with preselected information, new and more direct information and communication channels cause customer interactions to become more complex. Due to the emergence of ubiquitously available communication channels, single points of interaction are replaced by multiple touchpoints throughout the entire value chain, so that enterprisespecific processes and operations become increasingly visible to outside stakeholders. For example, as multichannel retailing is important for telecommunication service providers to address different segments of customers, providing consistent information on prices, terms and conditions, and product information affects customer satisfaction significantly. As the $\mathrm{CC}$ aims to acquire a comprehensive understanding of a product across different retailing channels, he or she considers information from brick-and-mortar subsidiaries, web shops, and customer call services. By receiving different offers from the same retailer, customers frequently lose track and reassess their purchasing decision. Using the method of service blueprinting, Figure 2 illustrates the change in customer interactions. 


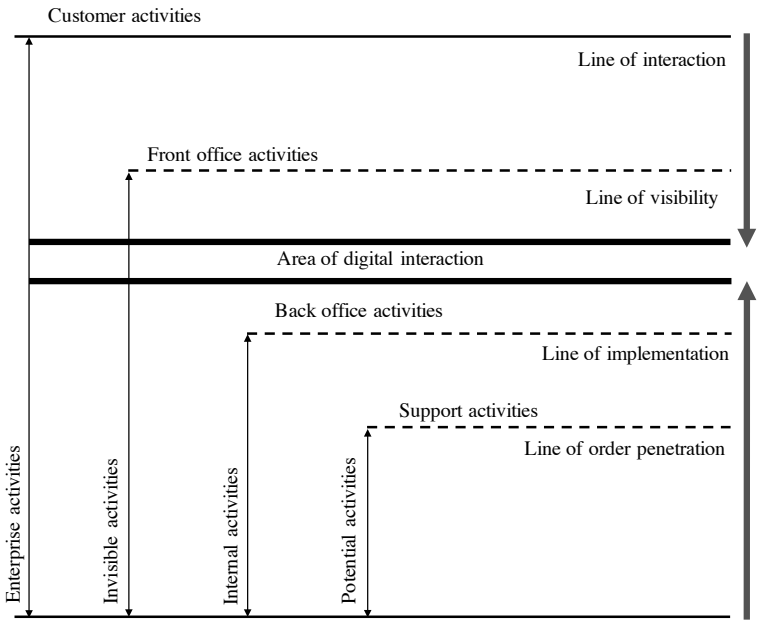

Figure 2. Customer-Enterprise interactions [51]

We can divide potential activities into customer activities, front office activities, back office activities, and support activities [51]. First, customer activities describe customers interacting in the service delivery process. Second, we summarize opportunities for enterprises and customers to communicate directly by front office activities. By initiating an interaction using any available channel, customers cross the line of interaction, which separates customer actions from those of the service provider [9]. However, as all enterprise activities are reduced to this single interaction, either resulting in customer satisfaction or discontent, we refer to crossing the line of interaction as a moment of truth [9]. As it significantly influences customer satisfaction, enterprises rely on the coordination of activities and business operations. Third, back office activities are defined as preparatory steps, as their outcomes provide necessary information for the front office. Both types of activities are separated by the line of visibility, as back office activities are typically not perceived by the customer directly [49]. Finally, support activities are not involved in the process of service delivery and thus, do not add value to the service directly. However, they support an enterprise's operations indirectly and are separated by the line of implementation [9].

An enterprise's value creation is based on the vertical connection of cross-functional activities through communication and coordination to address customer requirements adequately in each moment of truth [20]. Due to internal and external influence factors, enterprises can change the position of their separation lines to initiate business process reengineering, process optimization, and other organizational change projects. However, as technology advances, separation lines are repositioned automatically and gradually merge into the area of digital interaction. Due to the individualization of products and services, customer interactions and business operations become more complex and demand more cross-functional integration, coordination, and communication. On the one hand, separation lines are crossed more frequently and faster. On the other hand, all activities of an enterprise move closer to the line of visibility, revealing an enterprise's internal operations and procedures to the customer.

\section{Enabling technologies for connected enterprises}

Please note that Times New Roman is the preferred font for the text of you paper. If you must use another font, the following are considered base fonts. You are encouraged to limit your font selections to Helvetica, Arial, and Symbol as needed. These fonts are automatically installed with the viewing software.

\subsection{Implement a decentralized management of processes}

We address an enterprise's process and business architecture through a decentralized management of business processes. Business processes integrate systems, data, and resources, define tasks, jobs, and responsibilities, and enable the efficient management and distribution of knowledge [16]. Based on their capabilities to organize, structure, and align an enterprise's operations, methods of Business Process Management (BPM) are crucial for the design and management of organizations [8]. As the $\mathrm{CC}$ accesses unlimited information in real time, enterprises must increase their organizational responsiveness. Thus, adequate BPM procedures that consider organizational and technological aspects for process optimization are necessary. Consequently, enterprises can increase the benefit of BPM initiatives by establishing a processoriented mindset throughout the entire organization. As many enterprises are still organized along functional departments, the adoption of process-orientation is fundamental for BPM success. Typically based on a top-down design, traditional initiates have proven to be highly efficient in passing goals and strategies through the organization [26]. However, managing processes top down can be costly and time consuming. As enterprises aim to maximize their profits, BPM activities are focused on the processes that promise the highest expected returns on investment [16]. Consequently, support processes or less important activities are neglected and not managed appropriately [19]. As the emergence of numerous new customer touchpoints increases interdependencies, enterprises 
risk that non-competitive processes become visible to outside stakeholders, negatively influencing customer satisfaction.

Decentralizing BPM can improve an enterprise's responsiveness while increasing competitiveness in a dynamically changing environment [27]. In line with that, a set of best practice procedures has been defined to establish process-orientation as an organization-wide mindset, facilitating the adoption of corresponding tools and mechanisms [27]. To implement a bottom-up BPM design, enterprises must satisfy three preliminaries. First, they must implement an integrated, organization-wide modeling environment [26]. By enabling the modelling of tasks and activities where they are performed, business processes can be formally represented and shared with other employees. Thus, this process facilitates communication and coordination and initiates decentralized process optimization, for example, by revealing interfaces, redundancies, and inconsistencies. Second, enterprises must provide a central information platform that allows to access process models ubiquitously [26]. Thus, stored models are structured and organized, enabling users to search for relevant business processes, for example, to align upstream and downstream activities. Enterprises can further provide best practices, use the generated data to identify faulty processes, determine their competitiveness, or evaluate their contribution to enterprise success [26]. Finally, they must offer appropriate incentives to potential users that facilitate their adoption and participation decision [26].

\subsection{Minimize coordination and communication costs}

We further address an enterprise's integration and software architecture by implementing information systems capable of reducing costs for coordination and communication. As production and service delivery increasingly depend on other members of a value network, enterprises must address these costs by information technology. To support intraorganizational and inter-organizational business operations, enterprises must further integrate processes, data, and information systems in use. However, many enterprise architectures comprise a set of best-of-breed solutions, which are suitable within their specific field of application [30]. However, integrating these systems can be complex, costly, and time consuming [18]. Additionally, aligning software solutions to fit enterprise-specific needs hampers the implementation of new software releases and negatively influences system performance.

Enterprise resource planning (ERP) systems are a special class of information systems that support business operations by providing a central and integrated database. Typically distributed as standardized software, ERP systems allow enterprises to reuse an industry's best practices and to improve their efficiency and effectivity [23]. Based on the integration of data throughout the entire organization, they improve an enterprise's responsiveness and enable flexible and satisfactory customer interactions [23]. Offering a cross-functional management of organizational resources, ERP systems can reduce process costs and increase the quality of customer services $[8,14,52]$.

However, as enterprises become more interconnected, process and data integration cannot be limited to a single organization. In fact, extensive risks caused by interdependencies between supply chain members require a throughout integration of e-business activities. Consequently, e-business standards enable the cross-organizational automation of business processes and data exchange, supporting each steps of the value creation process, including the identification, classification, categorization, and transaction of products and services. Standards for identification provide a unique identification number to identify a product within the supply chain. Additionally, standards for classification foster unambiguous product descriptions to structure their characteristics and attributes. Standards for data exchange enable enterprises to exchange catalogues that comprise relevant product data. Finally, transaction standards facilitate the exchange of transaction objects, such as invoices and orders, and enable the automation of supply chain operations.

\subsection{Analyze business operations in real time}

We address the software and technology architecture by implementing mechanisms and techniques to analyze business operations in real time. Effectively performing Business Intelligence (BI) to predict future developments is among the key success factors for providing customer-oriented services [5]. Although data-driven manufacturing and service engineering have gained tremendous importance in recent years, many enterprises build upon historic data and standardized reports to manage their strategy, goals, and resources. However, as the amount of available data fundamentally increases, enterprises must provide the necessary capabilities to analyze and process data more accurately and faster [17, 28]. Due to the availability of digital communication channels, enterprises face new challenges when interacting with the CC. To capture potential benefits, for example, by adjusting marketing strategies to customer reactions, or reducing risks resulting from negative reviews and the 
corresponding loss of reputation, enterprises must use information systems that facilitate data collection, processing, and analysis for a real-time decision support.

Concepts of real-time analytics are typically characterized by their event-based initialization. While traditional event processing describes methods of tracking and processing data streams about occurring events from a single source of information, complex event processing combines data from multiple sources to identify patterns, derive implications, and optimize an enterprise's business operations [31]. Thus, organizations can gain a comprehensive understanding of their business environment and increase the quality of available data for decision making [11]. The range of analyzable data includes news items, text messages, social media posts, stock market feeds, traffic reports, and weather reports. In combination with an eventdriven architecture, complex event processing enables enterprises to not only analyze the performance of but also manage their business processes in real time.

\subsection{Determine the optimal degree of connectivity}

Effective BPM initiatives, an integrated system architecture, and capabilities to collect, store, and analyze data in real time determine the key drivers for enterprise success when interacting with the $\mathrm{CC}$ within the IoE. Although implementing adequate resources facilitates the management and optimization of an enterprise's business operations, IT projects typically come with tremendous demands on time and costs. Thus, decision making requires an in-depth analysis of enterprise-specific needs, including desired increases in performances, targeted cost efficiency, and expected financial surpluses [40]. Although benefits of implementing a flexible EA typically result from the organization-wide support of business processes and corresponding increases in organizational responsiveness, IS-related research provides only little empirical evidence on the relationship of IT investments and financial performance indicators. However, from an economic perspective, these endeavors are essentially influenced by two opposing aspects, which are illustrated in Figure 3.

According to [25], cost efficiency of IT investments depends heavily on the expected improvements in organizational responsiveness. Consequently, as a low responsiveness results in fewer action candidates for operational and strategic decision making, enterprises face higher opportunity costs, negatively influencing their profit opportunities [25].

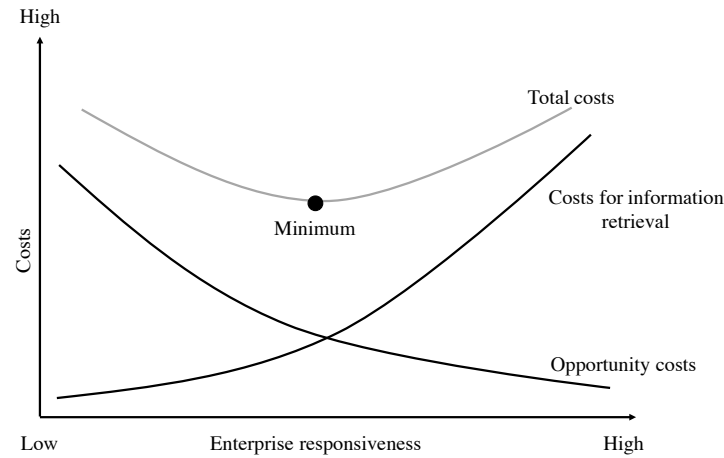

Figure 3. Optimal degree of connectivity

Although implementing real-time IT infrastructures can significantly increase an organization's responsiveness, system complexity results in increasing costs for information retrieval. To determine the optimal degree of connectivity, enterprises must find an adequate relationship between opportunity and information retrieval costs that minimizes the total costs of EA implementation [40].

\section{Conclusion}

As people, places, and products become more interconnected, the physical world is gradually merging with the virtual world into the IoE. While efficient manufacturing, innovative marketing activities, and product design were among the key drivers for business success in the past, the IoE has resulted in more service-centered customer demands. Thus, stand-alone products are replaced by hybrid product-service combinations, with the benefit of product usage influenced by complementary services.

Based on a ubiquitous Internet accessibility, customers connect with their environment. Thus, they can access unlimited information, share their experiences and opinions with others, and communicate with enterprises on various communication channels. To accomplish customer satisfaction, enterprises must obtain a comprehensive understanding of customer needs and initiate a transformation towards a connected enterprise. By introducing the $\mathrm{CC}$, we provide an overview of current customer characteristics and needs. A collection of guidelines enables enterprises to address these needs, while managing their operations in the IoE. Building upon established EA, the predefined guidelines were then transformed into practical recommendations using a DSR procedure. Addressing the business and process layer, enterprises must accomplish an organizationwide process-orientation to continuously improve their business operations. As top-down initiatives can only partially manage organizational structures, 
decentralized and collaborative BPM approaches are necessary for a holistic management. At the data and software layer, enterprises can minimize their costs for coordination and communication by implementing ERP systems. Complemented by e-business standards, enterprises can further reduce coordination costs within the entire supply chain. Finally, the software and technology layer can be complemented by techniques for real-time data analysis that allow enterprises to immediately respond to environmental changes.

However, approaches of this kind have a variety of well-known limitations. First, the derived guidelines are based on customer characteristics, drawn from empirical observations and findings within the literature. Additionally, the proposed components to address the different layers of the enterprise architecture only account for a fraction of available technologies, which were not discussed in this analysis. Thus, future research should focus on performing more detailed investigations on the needs, preferences, and characteristics of the CC. Technologies that were neglected in this contribution should further be analyzed towards their ability to address the complex requirements of the $\mathrm{CC}$. In addition, more diversified influence factors must be integrated into the optimal connectivity decision. Finally, more research is necessary to fully understand the $\mathrm{IoE}$ and the interdependencies between its dimensions.

\section{References}

[1] A. Payne and P. Frow, "A Strategic Framework for Customer Relationship Management”, Journal of Marketing, 2005, pp. 167176.

[2] Aier, S., „Enterprise Application Integration: Serviceorientierung und nachhaltige Architekturen“, Gito-Verlag, Berlin, 2006.

[3] P. Aula, "Social Media, Reputation Risk and Ambient Publicity Management”, Strategy \& Leadership, 2010, pp. 43-49.

[4] Axel, K., "Location-based Services: Fundamentals and Operation”, John Wiley \& Sons, Chichester, 2005.

[5] B. Azvine, Z. Cui, and D.D. Nauck, "Towards Real-time Business Intelligence", BT Technology Journal, 2005, pp. 214 225.

[6] E. Bakshy, I. Rosenn, C. Marlow, and L. Adamic, "The Role of Social Networks in Information Diffusion", Proceedings of the 21st International Conference on World Wide Web, 2012, pp. 519-528.

[7] R. Baskervile, J. Pries-Heje, and J. Venable, "Soft Design Science Methodology", Proceedings of the 4th International Conference on Design Science Research in Information Systems and Technology, ACM Press, 2009, Art. No. 9.

[8] Becker J., M. Kugeler, and M. Rosemann, "Process
Management: A Guide for the Design of Business Processes”, Springer Science \& Business Media, Berlin, 2013.

[9] M. J. Bitner, A.L. Ostrom, and F.N. Morgan, "Service Blueprinting: A Practical Technique for Service Innovation", California management review, 2008, pp. 66-94.

[10] G. Briscoe and P.De. Wilde, "Digital Ecosystems: Evolving Service-orientated Architectures", Proceedings of the International Conference on Bio-inspired Models of Network, Information, and Computing Systems, 2006, Art. No. 17.

[11] Chandy, K. and W. Schulte, "Event Processing: Designing IT Systems for Agile Companies", McGraw-Hill Inc., New York, 2010.

[12] Cook, M.A., "Building Enterprise Information Architectures: Reengineering Information Systems", Prentice-Hall Inc., New York, 1996.

[13] C. Czarnecki, A. Winkelmann, and M. Spiliopoulou, "Transformation in Telecommunication - Analyse und Clustering von Real-Life-Projekten", Proceedings of the Multikonferenz Wirtschaftsinformatik, 2012, pp. 985-997.

[14] T.H. Davenport, "Putting the Enterprise into the Enterprise System”, Harvard Business Review, 1998.

[15] D. Draheim and G. Weber, "Trends in Enterprise Application Architecture", TEAA, 2005.

[16] Dumas, M., M. La Rosa, J. Mendling, and H.A. Reijers, "Fundamentals of Business Process Management", Springer, Berlin, 2013.

[17] M. Eckert, and F. Bry, "Complex Event Processing (CEP)", Informatik-Spektrum, 2009, pp. 163-167.

[18] M. Fischer, D. Heim, C. Janiesch, and A. Winkelmann, "Assessing Process Fit in ERP Implementation Projects: A Methodological Approach", Proceedings of the 12th Conference on Design Science Research in Information Systems, 2017, pp. 320.

[19] M. Fischer, F. Imgrund, C. Janiesch, and A. Winkelmann, "Corpus Statistics for Measuring Business Process Similarity", Proceedings of the 23st Americas Conference on Information Systems, 2017.

[20] Fließ, S., „Prozessorganisation in Dienstleistungsunternehmen“, W. Kohlhammer Verlag, Stuttgart, 2006.

[21] A. M. French, R.S. Louis, B. Stevens, and J. Clark, "Sailing the Seven Seas, a Blue Ocean of the Internet of Things", Proceedings of the 21st Americas Conference on Information Systems, 2015.

[22] C. Gröger, F. Niedermann, and B. Mitschang, "Data Miningdriven Manufacturing Process Optimization", Proceedings of the World Congress on Engineering, 2012, pp. 4-6.

[23] N. Gronau, „E-Business mit ERP-Systemen“, Industrie Management, 2001, pp. 64-78.

[24] J. Gubbi, R. Buyya, S. Marusic, and M. Palaniswami, 
"Internet of Things (IoT): A Vision, Architectural Elements, and Future Directions", Future Generation Computer Systems, 2013, pp. 1645-1660.

[25] R. Hackathorn, "Minimizing Action Distance", DM Review, 2002, pp. 22-23.

[26] F. Imgrund, M. Fischer, C. Janiesch, and A. Winkelmann, "Managing the Long Tail of Business Processes", Proceedings of the 25th European Conference on Information Systems, 2017.

[27] Imgrund, F., C. Janiesch, and C. Rosenkranz, ““'Simply Modeling" - BPM from Everybody: Recommendations from the Viral Adoption of BPM at 1\&1", Business Process Management: Cases, Springer, Berlin, 2017.

[28] C. Janiesch, M. Matzner, and O. Müller, "A Blueprint for Event-Driven Business Activity Management”, Proceedings of the 9th International Conference on Business Process Management, 2011, pp. 17-28.

[29] A. Kees, A.M. Oberländer, M. Röglinger, and M. Rosemann, "Understanding the Internet of Things: A Conceptualisation of Business-to- Thing (B2T) Interactions", Proceedings of the 23rd European Conference on Information Systems, 2015.

[30] B. Light, C.P. Holland, and K. Wills, "ERP and best of breed: a comparative analysis", Business Process Management Journal, 2001, 216-224.

[31] Luckham, D., "The Power of Events", Addison-Wesley Reading, Boston, 2002.

[32] E.C. Malthouse, M. Haenlein, B. Skiera, E. Wege, and M. Zhang, "Managing Customer Relationships in the Social Media Era: Introducing the Social CRM House", Journal of Interactive Marketing, 2013, pp. 270-280.

[33] W.G. Mangold and D.J. Faulds, "Social Media: The New Hybrid Element of the Promotion Mix", Business Horizons, 2009, pp. 357-365.

[34] A. McAfee, E. Brynjolfsson, T.H Davenport, D.J. Patil, and D. Barton, "Big data: The Management Revolution", Harvard Business Review, 2012, pp. 61-67.

[35] D. Miorandi, S. Sicari, F. De Pellegrini, and I. Chlamtac, "Internet of Things: Vision, Applications and Research Challenges", Ad Hoc Networks, 2012, pp. 1497-1516.

[36] J. Miranda, N. Mäkitalo, J. Garcia-Alonso, et al., "From the Internet of Things to the Internet of People", IEEE Internet Computing, 2015, pp. 40-47.

[37] Morandi, C., A. Rolando, and S. di Vita, "From Smart City to Smart Region", Springer International Publishing, Cham, 2016.

[38] F. Niederman, J.C. Brancheau, and J.C. Wetherbe, "Information Systems Management Issues for the 1990s", MIS Quarterly, 1991, pp. 475-500.

[39] H. Öğüt and B.K Onur Taş, "The Influence of Internet Customer Reviews on the Online Sales and Prices in Hotel Industry", The Service Industries Journal, 2012, pp. 197-214.
[40] L. Olsson and C. Janiesch, "Real-time Business Intelligence und Action Distance: Ein konzeptionelles Framework zur Auswahl von BI-Software", Proceedings of the 12th Internationalen Tagung Wirtschaftsinformatik, 2015, pp. 691705 .

[41] Palfrey, J.G. and U. Gasser, "Born Digital: Understanding the First Generation of Digital Natives", Basic Books, New York, 2013.

[42] K. Peffers, T. Tuunanen, M.A. Rothenberger, and S. Chatterjee, "A Design Science Research Methodology for Information Systems Research", Journal of Management Information Systems, 2007, pp. 45-77.

[43] G. Santucci, "The Internet of Things: Between the Revolution of the Internet and the Metamorphosis of Objects", Vision and Challenges for Realising the Internet of Things, 2010, pp. 11-24.

[44] Schiller, J. and A. Voisard, "Location-based Services", Elsevier, Amsterdam, 2004.

[45] M. Silver, "The Anatomy of a Connected Customer", 2017.

[46] Stata, R. and P. Almond, "Organizational Learning: The Key to Management Innovation", The training and development sourcebook, Amherst, 1989, pp. 31-42.

[47] The Open Group. TOGAF® Version 9.1 "Enterprise Edition.”, 2017.

[48] L. Urbaczewski and S. Mrdalj, "A Comparison of Enterprise Architecture Frameworks", Issues in Information Systems, 2006, pp. 18-23.

[49] Vermesan, O. and P. Friess, "Internet of Things: Converging Technologies for Smart Environments and Integrated Ecosystems", River, Aalborg, 2013.

[50] Weinman, J., "Digital Disciplines: Attaining Market Leadership via the Cloud, Big Data, Mobility, Social Media, and the Internet of Everything”, John Wiley \& Sons, Hoboken, 2015.

[51] Wilson, A., V.A. Zeithaml, M.J. Bitner, and D.D. Gremler, "Services Marketing: Integrating Customer Focus Across the Firm”, McGraw Hill, New York, 2012.

[52] A. Winkelmann and K. Klose, "Experiences while Selecting, Adapting and Implementing ERP Systems in SMEs: A Case Study", Proceedings of the 14th Americas Confence on Information Systems, 2008.

[53] R. Winter and R. Fischer, "Essential Layers, Artifacts, and Dependencies of Enterprise Architecture", Enterprise Distributed Object Computing Conference Workshops, 2006.

[54] F. Wortmann and K. Flüchter, "Internet of Things", Business \& Information Systems Engineering, 2015, pp. 221-224.

[55] C. Young, "The Unexpected Case for Enterprise IT Architectures”, Gartner Group Strategy, Trends \& Tactics, 2001.

[56] J.A Zachman, "A Framework for Information Systems Architecture", IBM Systems Journal, 1987, pp. 276-292. 